\title{
FABRICATION AND CHARACTERIZATION OF C/C-SIC MATERIAL MADE WITH PITCH-BASED CARBON FIBERS
}

\author{
Thomas Reimer, Ivaylo Petkov, Dietmar Koch, Martin Frieß, Christoph Dellin \\ DLR, German Aerospace Center, Institute of Structures and Design \\ Pfaffenwaldring 38-40, 70569 Stuttgart, Germany
}

Keywords: CMC, C/C-SiC, carbon fiber, pitch fiber, thermal conductivity, re-entry

\section{ABSTRACT}

During atmospheric re-entry high thermal loads are generated on the surface of the entry vehicle with peak loads in the stagnation area. Typical entry vehicles have a blunt shape avoiding sharp tips or leading edges because the heat load increases with a decreasing curvature radius of the surface structure. Recent developments for vehicles in the hypersonic flight regime have concentrated on sharp designs to reduce drag and increase lift. This creates challenges with regard to the materials used for the tip or leading edge of the vehicle. Ceramic matrix composites are materials with good high-temperature properties, however, the thermal loads on sharp structures can exceed even their capabilities. One way to relieve the problem could be to use a material at the structure tip with a very high thermal conductivity to distribute the heat load over a wider area and thereby reducing the temperature to an acceptable level. In this work a C/C-SiC ceramic matrix composite made with pitch carbon fibers was fabricated and characterized. Different types of pitch carbon fibers were procured and sample plates were manufactured. The thermally relevant properties were measured as there are thermal diffusivity, density and specific heat capacity and with that the thermal conductivity was calculated. In addition basic mechanical properties were measured to evaluate the material from a structural point of view.

\section{INTRODUCTION}

High thermal loads are present on the surface of a re-entry vehicle during atmospheric descent with peak loads in the stagnation area. In order to control this, typical entry vehicles have a blunt shape avoiding sharp tips or leading edges. Recent developments to increase the aerodynamic efficiency of such vehicles in the hypersonic flight regime have, however, concentrated on designs that rely especially on slender shapes featuring sharp leading edges to reduce drag and increase lift ${ }^{1}$. This creates challenges with regard to the materials used for the tip or leading edge of the vehicle because heat loads increase with the reduction of the curvature radius $^{2}$. Materials used for the stagnation areas of blunt vehicles with a re-usable TPS were C/C as e.g. for the nose and leading edges of the Space Shuttle ${ }^{3}$. Another Ceramic Matrix Composite (CMC) is C/C-SiC which was used for the X-38 nose ${ }^{4}$. These materials are limited in their maximum use temperature to around $1600-1700^{\circ} \mathrm{C}$ which is mainly due to the limited performance of protective coatings against oxidation effects. In an attempt to increase the maximum use temperature of such TPS materials Ultra High Temperature Ceramics (UHTC) are proposed for sharp structures and were already flown on test flights e.g. as the SHARP experiments $^{5,6}$. As an alternative method active cooling is investigated and proposed for the leading edge of the SHEFEX vehicle in the form of transpiration cooling ${ }^{7}$. Another option which shall be discussed in this work could be to increase the thermal conductivity of the material used for a tip or leading edge. The rationale behind this approach is that the heat load on a sharp leading edge is concentrated in a relatively small region around the leading edge and that it is decreasing rapidly when moving downstream. So, if a material with a very high thermal 
conductivity was available, the heat could be transported from the leading edge to regions with lower heat loads, thereby lowering the temperature of the leading edge.

\section{CERAMIC MATRIX COMPOSITE C/C-SIC}

The CMC which is produced at the Institute of Structures and Design of DLR in Stuttgart is made from carbon fibers which are embedded in a matrix of carbon and silicon carbide and it is thus refered to as $\mathrm{C} / \mathrm{C}$-SiC. The fibers are standard industrial grade HT fibers with a relatively low thermal conductivity and so the overall resulting thermal conductivity of the CMC is not very high $^{8}$. The fabrication of $\mathrm{C} / \mathrm{C}$-SiC composites at DLR is divided into three steps. In the first step, a carbon fiber reinforced polymer (CFRP) component is produced which can be performed in different ways. The preferred approaches are resin transfer molding (RTM) or autoclave technology, but warm pressing or filament winding are also accepted processes. After the curing, the composites are tempered for $4 \mathrm{hr}$ at $240^{\circ} \mathrm{C}$ to complete the polymerization of the matrix. It is essential to use a resin (e.g. phenolic) with high carbon yield in this step to create a matrix with sufficient carbon content in the subsequent step. In the second step, the CFRP composite is pyrolysed under inert atmosphere (nitrogen) at a temperature of $1650^{\circ} \mathrm{C}$ to convert the polymer matrix to amorphous carbon. The result is a porous $\mathrm{C} / \mathrm{C}$ component. The pyrolysis results in a macroscopic shrinkage of about $10 \%$ mainly in thickness and a microscopic network of cracks within the $\mathrm{C} / \mathrm{C}$ composite is formed. The fiber bundles remain practically intact. In the third step, the $\mathrm{C} / \mathrm{C}$ component is siliconized via melt infiltration. The component is placed into a coated graphite crucible and solid silicon is added as granulated pure metal. After heating up to over $1420^{\circ} \mathrm{C}$ (melting of silicon) the porous $\mathrm{C} / \mathrm{C}$ component is filled with liquid silicon due to the capillary effect of the micro-cracks and the low viscosity of the molten silicon. In an exothermic reaction between the molten silicon and the carbon matrix, silicon carbide is formed along the micro cracks encapsulating the carbon fiber bundles. The siliconizing is carried out under vacuum at a temperature of $1650^{\circ} \mathrm{C}$. The resulting $\mathrm{C} / \mathrm{C}$-SiC composites contain three material phases as shown in Figure 1 (a). These are the carbon phase (black/dark grey in the Figure) consisting of carbon fibers and residual carbon matrix, silicon carbide (light gray) as the main matrix constituent and a small share of unreacted free silicon (white).

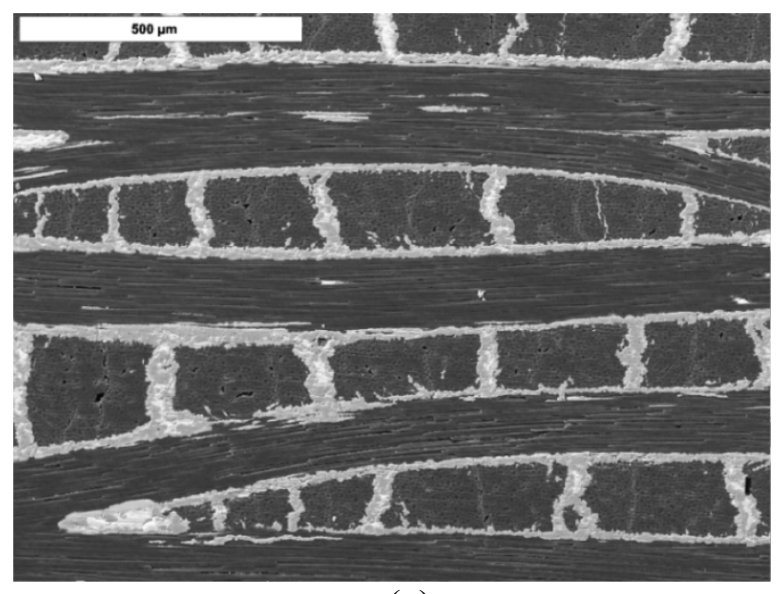

(a)

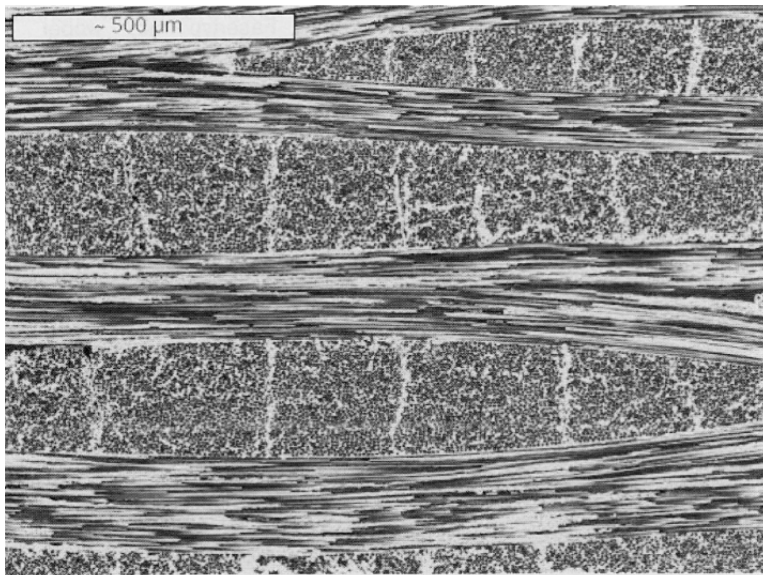

(b)

Figure 1. Microstructure of (a) standard $\mathrm{C} / \mathrm{C}-\mathrm{SiC}$ and (b) of $\mathrm{C} / \mathrm{C}-\mathrm{SiC}$ with low fiber matrix bond strength.

In order to increase the CMC conductivity, the conductivity of the fibers or that of the matrix or both can be improved. In this work, the focus was put on the fibers and it was investigated if the 
thermal conductivity of the $\mathrm{C} / \mathrm{C}$-SiC material can be improved using carbon fibers of high thermal conductivity.

\section{CARBON PITCH FIBERS}

There are three general classes of carbon fibers with regard to their manufacturing and precursors. First, there are the PAN fibers made by processing polyacrylnitril. Second, there are the pitch-based fibers made by processing pitch and last there are fibers produced from Rayon ${ }^{9}$. The conductivity of carbon fibers depends on the degree of orientation of the carbon molecules in the fiber relative to the longitudinal axis. This goes along with the mechanical property of the Young's modulus which is increasing with higher orientation. Pitch fibers can be graphitized to a higher degree than PAN fibers. This increases the thermal conductivity considerably. Pitch fibers with a thermal conductivity of up to $1000 \mathrm{~W} / \mathrm{mK}$ are available on a lab scale compared to 15 $\mathrm{W} / \mathrm{mK}$ for the currently used PAN-based HT fibers ${ }^{10}$. For this study, processing investigations were made to fabricate a high-conductivity CMC via melt infiltration technology using pitch fibers. The fibers that were selected for the investigations were two types, namely the Mitsubishi K63A12 and the Nippon Graphite NGF SF-YS95A-100 fiber with a thermal conductivity of 220 $\mathrm{W} / \mathrm{mK}$ and $600 \mathrm{~W} / \mathrm{mK}$ respectively.

Table I: Pitch Carbon Fiber Properties

\begin{tabular}{|l|c|c|c|}
\hline \multicolumn{2}{|c|}{} & Nippon Graphite Fiber Corp. & Mitsubishi Plastics \\
\hline Fiber Type & & YS-95A & K63A12 \\
\hline Tensile Strength & $\mathrm{MPa}$ & 3530 & 2600 \\
\hline Tensile Modulus & $\mathrm{GPa}$ & 920 & 790 \\
\hline Ultimate Elongation & $\%$ & 0.3 & 0.3 \\
\hline Density & $\mathrm{kg} / \mathrm{m}^{3}$ & 2.19 & 2.15 \\
\hline Filament Diameter & $\mu \mathrm{m}$ & 7 & $12 *$ \\
\hline Filaments per Yarn & & $3 \mathrm{~K}$ & $12 \mathrm{~K}$ \\
\hline Yield & $\mathrm{g} / \mathrm{km}$ & 250 & 1950 \\
\hline CTE & $10-6 / \mathrm{K}$ & -1.5 & -1.2 \\
\hline Thermal Conductivity & $\mathrm{W} / \mathrm{m}^{*} \mathrm{~K}$ & 600 & 220 \\
\hline Electrical Resistivity & $\mu \Omega \mathrm{m}$ & 2.2 & $4 \sim 5$ \\
\hline Fabric Area Weight & $\mathrm{g} / \mathrm{m}^{2}$ & 100 & 817.4 \\
\hline
\end{tabular}

\section{SAMPLE MANUFACTURING}

First fabrication trials had shown that the fiber matrix bond is rather weak. This leads to a different microstructure than with the standard C/C-SiC. Whereas the typical microstructure of $\mathrm{C} / \mathrm{C}-\mathrm{SiC}$ is characterized by a segmentation into compact large blocks of filaments encapsulated by silicon carbide as a whole as shown in Figure 1 (a), the microstructure of the pitch fiber CMC is quite different. There is almost no segmentation into larger structures but instead, the single filaments debond from the matrix so that the liquid silicon has access to the single filaments during the melt infiltration and a finely dispersed structure is created as shown in Figure 1 (b). Thus a higher amount of fibers is converted into $\mathrm{SiC}$ which affects the properties.In order to avoid this, the $\mathrm{C} / \mathrm{C}$ was re-infiltrated with the polymeric precursor. By this a layer of carbon is established around the single fibers The re-infiltration was done once and twice respectively on different samples of the same original plate. Three $\mathrm{C} / \mathrm{C}$-SiC plates with pitch carbon fibers were produced via the RTM method. Two fiber types were used, details of the respective fiber types are given in Table I. The fibers were available as a textile in plain weave. Rectangular pieces of 
295x91 mm were cut from it and stacked into the RTM mold. Different numbers of plies were stacked up because the fabric thickness and the plate thickness varied. Table II lists the details of the manufactured plates.

Table II: Sample plate details

\begin{tabular}{|c|c|c|c|c|c|c|}
\hline Plate & Fiber Type & Ply Number & $\begin{array}{c}\text { Length } \\
{[\mathrm{mm}]}\end{array}$ & $\begin{array}{c}\text { Width } \\
{[\mathrm{mm}]}\end{array}$ & $\begin{array}{c}\text { Thickness } \\
{[\mathrm{mm}]}\end{array}$ & $\begin{array}{c}\text { FVC } \\
{[\%]}\end{array}$ \\
\hline IP521 CFRP & $\begin{array}{c}\text { Mitsubishi } \\
\text { K63A12 }\end{array}$ & 18 & 300 & 90 & 12.9 & 48.2 \\
\hline IP523 CFRP & $\begin{array}{c}\text { Mitsubishi } \\
\text { K63A12 }\end{array}$ & 28 & 300 & 90 & 16.4 & 59.14 \\
\hline IP527 CFRP & $\begin{array}{c}\text { NGF } \\
\text { YS-95A }\end{array}$ & 220 & 150 & 90 & 16.4 & 56.1 \\
\hline
\end{tabular}

Before the pyrolysis, a small part was cut off the CFRP plates for reference purposes. After pyrolysis a sample of 20-25 mm length was cut from the C/C plate. The remaining C/C plate was infiltrated with phenolic resin again via RTM and pyrolysed again similar to the PIP method (Polymer Infiltration and Pyrolysis). The goal was to achieve a denser $\mathrm{C} / \mathrm{C}$ material with a higher carbon content of the matrix which was supposed to protect the fibers from the contact with liquid silicon during the melt infiltration. The manufactured plates had a dimension of $300 * 90$ $\mathrm{mm}$ for the Mitsubishi-fiber plates and 150*90 mm for the NGF-fiber plate. Figure 2 shows how the plates were cut step by step for the different processing steps.

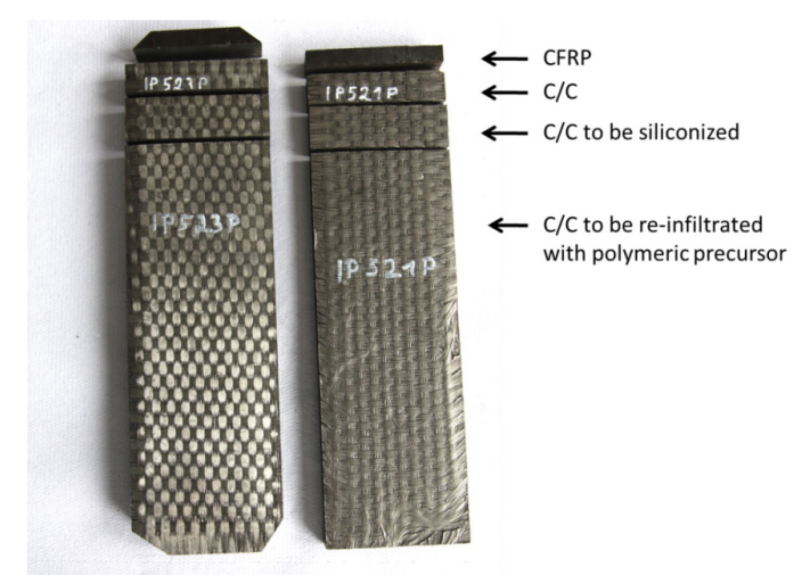

Figure 2. Usage of the manufactured sample plates.

\section{MATERIAL CHARACTERIZATION}

The density of the samples and the open porosity were determined via the Archimedesprinciple. The specific temperature-dependent heat capacity was measured via the Differential Scanning Calorimetry (DSC) method. The apparatus used was a Netzsch DSC 404. The samples had a diameter of $6 \mathrm{~mm}$ and a thickness of $2 \mathrm{~mm}$. The mass of the sample was measured with a precision scale. The specific heat was measured up to a temperature of $600^{\circ} \mathrm{C}$ and for the correction values a sapphire sample was measured. The thermal diffusivity was measured with the Laser Flash Analysis (LFA) method. The apparatus that was used for the measurements was a Netzsch LFA 457. The samples had a diameter of $12.5 \mathrm{~mm}$ and a thickness between 3 and 4 $\mathrm{mm}$. Two different batches of samples had to be prepared in order to account for diffusivity dependency on the fiber orientation. The diffusivity was measured between $100^{\circ} \mathrm{C}$ and $900^{\circ} \mathrm{C}$ 
in intervals of $100^{\circ} \mathrm{C}$ under nitrogen atmosphere. The thermal conductivity is calculated from the diffusivity, specific heat and density.

$$
\lambda(T)=\alpha(T) \cdot c_{p}(T) \cdot \rho(T)
$$

For this study the density was considered constant because the $\mathrm{C} / \mathrm{C}$-SiC material has a very low coefficient of thermal expansion of $1.35 * 10^{-6} 1 / \mathrm{K}$ along the fibers and $5.48 * 10^{-6} 1 / \mathrm{K}$ perpendicular to the fibers. A mechanical characterization was carried out via short-beam threepoint bending tests following the standard DIN EN 658-5 using a Zwick/Roell 1494 test machine. It has to be noted that the results can only be used to compare materials of a similar kind which show a similar failure behavior. C/C-SiC will fail due to tension on the lower side whereas $\mathrm{C} / \mathrm{C}$ will fail due to shear. The sample size for the tree-point bending tests was $25 \mathrm{~mm}$ length, $10 \mathrm{~mm}$ width and $3 \mathrm{~mm}$ thickness. Visual inspections were done with a Zeiss Gemini scanning electrone microscope (SEM). In Table III an overview is given concerning density and open porosity, as well as dry mass und the mass of silicon taken up during the siliconization; there is also data from plates (PH1737, PH1659 and PH1815) reinforced with PAN-based HTA fibers that are later used for comparisons concerning the mechanical behavior.

Table III: Properties of the sample materials plus properties of three comparison plates.

\begin{tabular}{|c|c|c|c|c|c|c|}
\hline Sample & State & $\begin{array}{c}\mathrm{e}^{\prime} \\
{[\%]}\end{array}$ & $\begin{array}{c}\rho \\
{\left[\mathrm{g} / \mathrm{cm}^{3}\right]}\end{array}$ & $\begin{array}{c}\text { Dry Mass } \\
{[\mathrm{g}]}\end{array}$ & $\begin{array}{c}\text { Si-uptake } \\
\text { [g] }\end{array}$ & $\begin{array}{c}\text { Si-uptake } \\
{[\%]}\end{array}$ \\
\hline \multirow{2}{*}{ IP521-0 } & $\mathrm{C} / \mathrm{C}$ & 24.97 & 1.45 & 37.26 & & \\
\hline & C/C-SiC & 3.17 & 2.302 & 59.65 & 22.39 & 60.1 \\
\hline \multirow{2}{*}{ IP521-1 } & $\mathrm{C} / \mathrm{C}$ & 15.81 & 1.59 & 32.81 & & \\
\hline & C/C-SiC & 1.81 & 2.25 & 47.56 & 14.75 & 45.0 \\
\hline \multirow{2}{*}{ IP521-2 } & $\mathrm{C} / \mathrm{C}$ & 10.15 & 1.69 & 69.47 & & \\
\hline & C/C-SiC & 3.9 & 2.06 & 88.84 & 19.37 & 27.9 \\
\hline \multirow{2}{*}{ IP523-0 } & $\mathrm{C} / \mathrm{C}$ & 23.54 & 1.55 & 54.98 & & \\
\hline & $\mathrm{C} / \mathrm{C}-\mathrm{SiC}$ & 0.98 & 2.47 & 88.42 & 33.44 & 60.8 \\
\hline \multirow{2}{*}{ IP523-1 } & $\mathrm{C} / \mathrm{C}$ & 15.18 & 1.68 & 47.95 & & \\
\hline & C/C-SiC & 2.92 & 2.27 & 65.49 & 17.54 & 36.6 \\
\hline \multirow{2}{*}{ IP523-2 } & $\mathrm{C} / \mathrm{C}$ & 9.76 & 1.77 & 100.71 & & \\
\hline & $\mathrm{C} / \mathrm{C}-\mathrm{SiC}$ & 8.01 & 1.89 & 111.29 & 10.58 & 10.5 \\
\hline \multirow{2}{*}{ IP527-0 } & $\mathrm{C} / \mathrm{C}$ & 23.88 & 1.56 & 45.5 & & \\
\hline & C/C-SiC & 2.24 & 2.48 & 75.43 & 29.93 & 65.8 \\
\hline \multirow{2}{*}{ IP527-1 } & $\mathrm{C} / \mathrm{C}$ & 15.16 & 1.7 & 49.42 & & \\
\hline & C/C-SiC & 3.5 & 2.22 & 67.92 & 18.5 & 37.4 \\
\hline \multirow{2}{*}{ IP527-2 } & $\mathrm{C} / \mathrm{C}$ & 9.31 & 1.793 & 64.82 & & \\
\hline & $\mathrm{C} / \mathrm{C}-\mathrm{SiC}$ & 7.89 & 1.89 & 75.48 & 10.66 & 16.4 \\
\hline \multirow{2}{*}{ PH1737 } & $\mathrm{C} / \mathrm{C}$ & 14.55 & 1.34 & 2241.6 & & \\
\hline & $\mathrm{C} / \mathrm{C}-\mathrm{SiC}$ & 1.7 & 1.92 & 3203.5 & 961.9 & 42.9 \\
\hline \multirow{2}{*}{ PH1659 } & $\mathrm{C} / \mathrm{C}$ & 13.76 & 1.35 & & & \\
\hline & C/C-SiC & 3.11 & 1.82 & & & \\
\hline \multirow{2}{*}{ PH1815 } & $\mathrm{C} / \mathrm{C}$ & 12.11 & 1.38 & & & \\
\hline & $\mathrm{C} / \mathrm{C}-\mathrm{SiC}$ & 3.0 & 1.9 & & & \\
\hline
\end{tabular}

Nomenclature: -0: no re-infiltration; -1: re-infiltrated once; -2: re-infiltrated twice.

The changes in open porosity over the re-infiltration cycles are presented in Figure 3. Reinfiltration cycle 0 is the material condition after the first pyrolysis of the CFRP material. The 
values for the open porosity decrease for all three plates in a very similar fashion from approximately $25 \%$ to $10 \%$. This means that the re-infiltration worked well for all the plates.

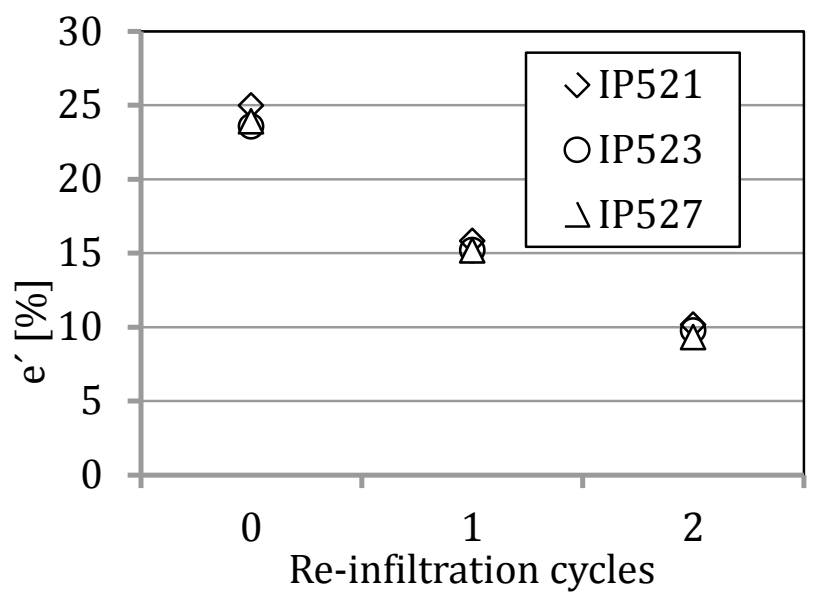

Figure 3. Open porosity of the $\mathrm{C} / \mathrm{C}$ samples over the re-infiltration cycles

(0: no re-infiltration; 1: one re-infiltration; 2: two re-infiltrations).

The corresponding data for the density of the $\mathrm{C} / \mathrm{C}$ samples is shown in Figure 4. According to the decrease in open porosity, the density increases similarly from approximately $1.5 \mathrm{~g} / \mathrm{cm}^{3}$ to $1.8 \mathrm{~g} / \mathrm{cm}^{3}$.

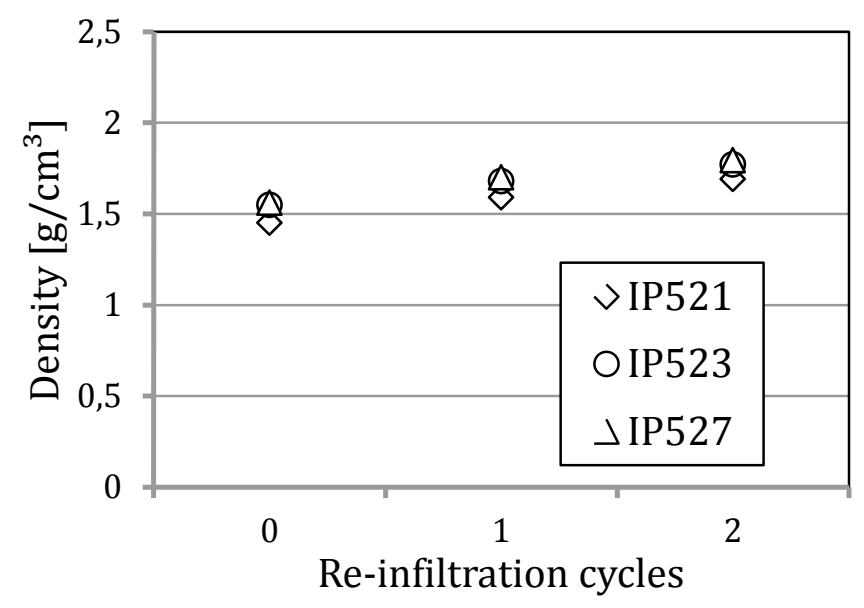

Figure 4. Density of the C/C samples over the re-infiltration cycles.

For the open porosity of the $\mathrm{C} / \mathrm{C}$-SiC samples, the picture is different as shown in Figure 5. In general, the porosity increases for all three plates from the initial condition to after the second reinfiltration. The plates IP523 and IP527 show this trend over both re-infiltration cycles. Only the first sample plate IP521shows a decrease in porosity from the initial condition to after the first re-infiltration from 3.2 to $1.8 \%$. After that its porosity increases from 1.8 to $3.9 \%$. 


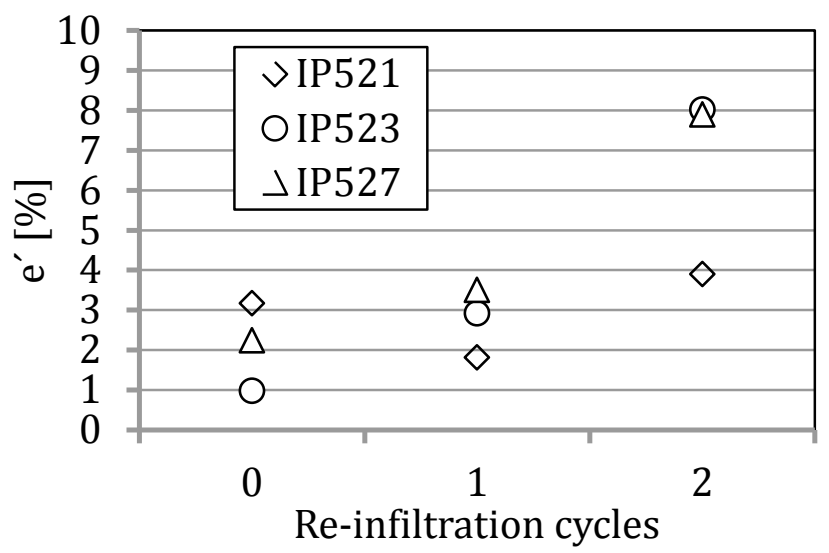

Figure 5. Open porosity of the C/C-SiC samples over the re-infiltration cycles.

The general trend to a higher porosity in the $\mathrm{C} / \mathrm{C}$-SiC condition after two polymeric reinfiltration cycles is explained with a limiting effect of shrinking micro-channel widths due to the polymeric re-infiltration. A minimum channel cross section is required to infiltrate sufficient liquid silicon and to build the silicon carbide matrix. If the micro channels are too small they are closed quickly blocking the way for further silicon. This results in an increased porosity. The effect is also reflected in the density values of the $\mathrm{C} / \mathrm{C}$-SiC samples. The density values decrease from around $2.4 \mathrm{~g} / \mathrm{cm}^{3}$ to $2 \mathrm{~g} / \mathrm{cm}^{3}$ as presented in Figure 6.

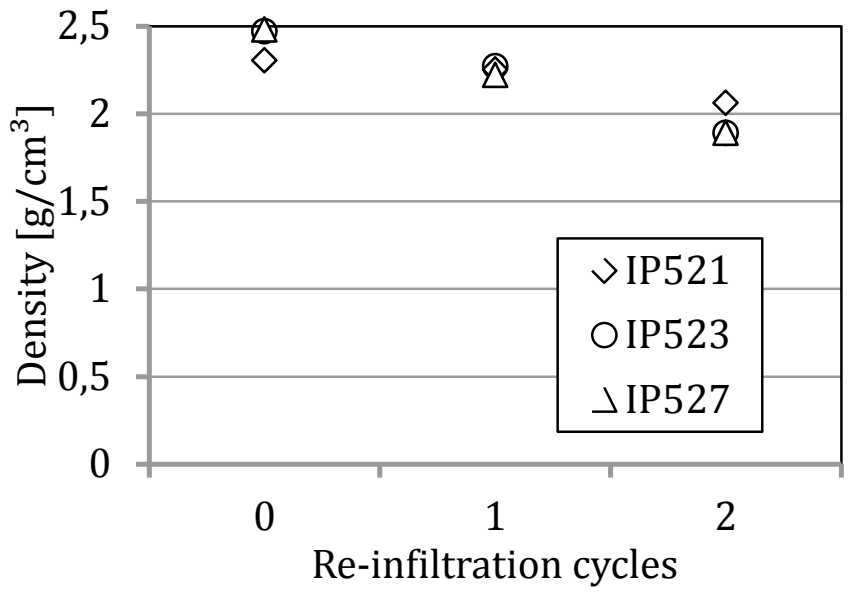

Figure 6. Density of the C/C-SiC samples over the re-infiltration cycles.

Thermal Material Characterization

The specific heat was measured in a Netzsch DSC 404 apparatus up to a temperature of $600^{\circ} \mathrm{C}$. The diffusivity measurements were made up to $900^{\circ} \mathrm{C}$. Therefore, to calculate the thermal conductivity up to $900^{\circ} \mathrm{C}$ the measurements of the specific heat were extrapolated from $600^{\circ} \mathrm{C}$ up to $900^{\circ} \mathrm{C}$ with a logarithmic function. The specific heat increases with each infiltration step which is due to the increasing carbon content of the material. This is supported by the fact that e.g. the specific heat for sample IP523- 0 in the $\mathrm{C} / \mathrm{C}$ condition at $80^{\circ} \mathrm{C}$ is at $1.2 \mathrm{~J} / \mathrm{gK}$ compared to 0.7 for the $\mathrm{C} / \mathrm{C}-\mathrm{SiC}$ condition.

In Figure 7 (a) the data for IP521 is shown. The data for the sample IP521-1 which was reinfiltrated one time is almost identical to the data of IP521-0 which was not re-infiltrated. 


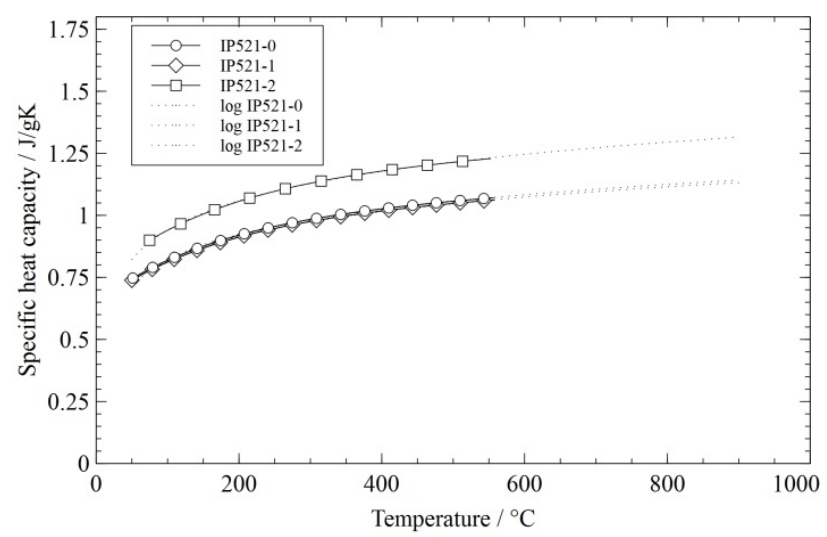

(a)

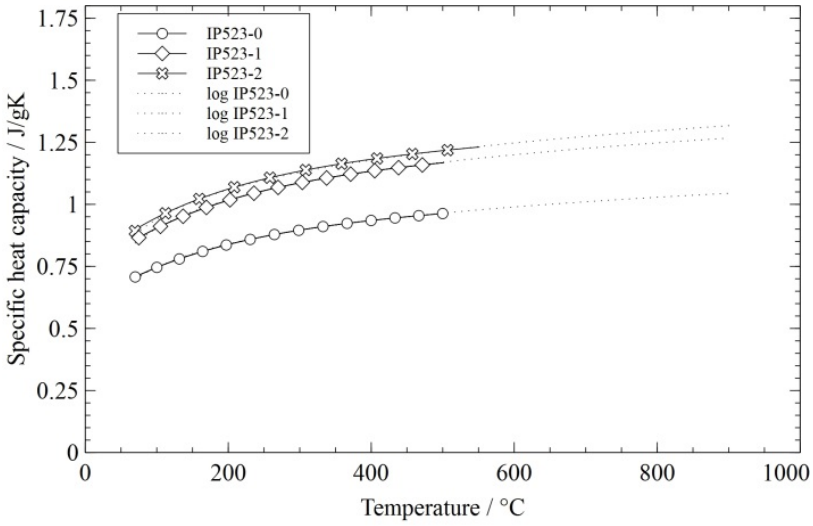

(b)

Figure 7. Specific heat of (a) IP521 and (b) IP523 in the C/C-SiC state.

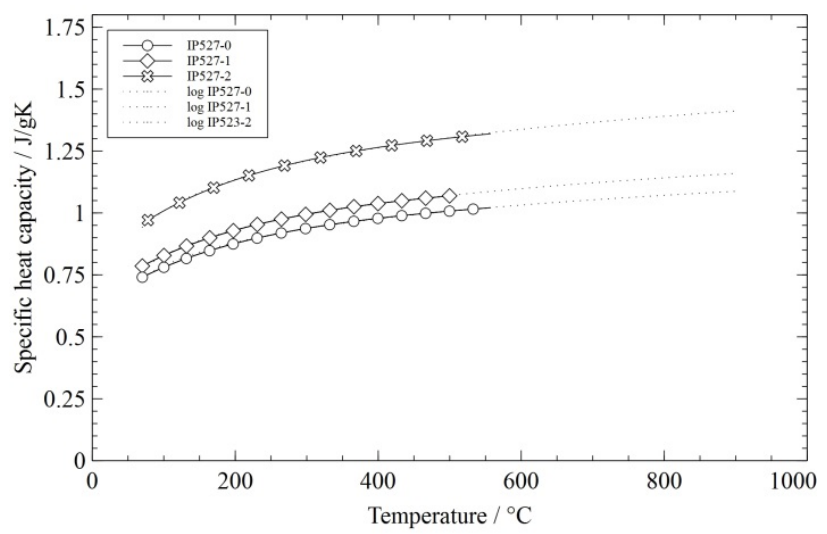

Figure 8. Specific heat of IP527 in the C/C-SiC state.

The thermal diffusivity was measured with the LFA method. Since the thermal diffusivity depends on the fiber direction in the material, each material was evaluated in two directions, first in the direction parallel to the fibers and, second, in the direction perpendicular to the fibers. Since the calculated data for the thermal conductivity follows the measured data of the diffusivity quite well, the measurement data for the diffusivity is not presented but instead the conductivity which is of greater practical interest.

The thermal conductivity is calculated according to (1) from the values of the density, specific heat and thermal diffusivity. Figures 11 to 13 show the conductivity data that was thus obtained from the measurements.

In Figure 9 the thermal conductivity of IP521 is presented. In the fiber direction the highest thermal conductivity value was measured with $95 \mathrm{~W} / \mathrm{mK}$ at $100^{\circ} \mathrm{C}$ for the sample that was reinfiltrated one time. The conductivity of the sample that was re-infiltrated twice is much lower with a peak value of $55 \mathrm{~W} / \mathrm{mK}$. The conductivity decreases with increasing temperature. Another observation was that the re-infiltration and the corresponding silicon uptake have an influence on the diffusivity and thus on the conductivity.

The conductivity perpendicular to the fibers is on a much lower level starting at $30 \mathrm{~W} / \mathrm{mK}$ at $100^{\circ} \mathrm{C}$ for the sample which was not re-infiltrated and 21 and $12 \mathrm{~W} / \mathrm{mK}$ for the samples with one and two re-infiltrations respectively. Also these values decrease with increasing temperature. 


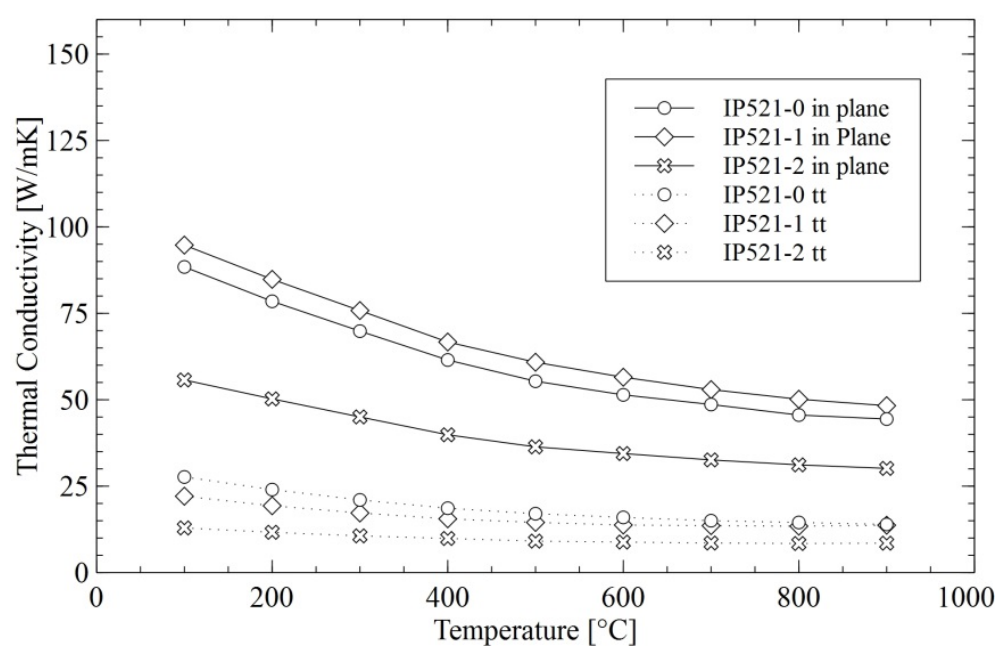

Figure 9. Thermal conductivity of IP521.

The data from the measurements of the IP523 samples is shown in Figure 10. The values of the samples that were not re-infiltrated and re-infiltrated once are very close together. A maximum of $115 \mathrm{~W} / \mathrm{mK}$ is reached at $100^{\circ} \mathrm{C}$. At $900^{\circ} \mathrm{C}$ the conductivity has decreased to just below 60 $\mathrm{W} / \mathrm{mK}$. The conductivity of the sample that was re-infiltrated twice is much lower and comes close to $70 \mathrm{~W} / \mathrm{mK}$ at $100^{\circ} \mathrm{C}$.

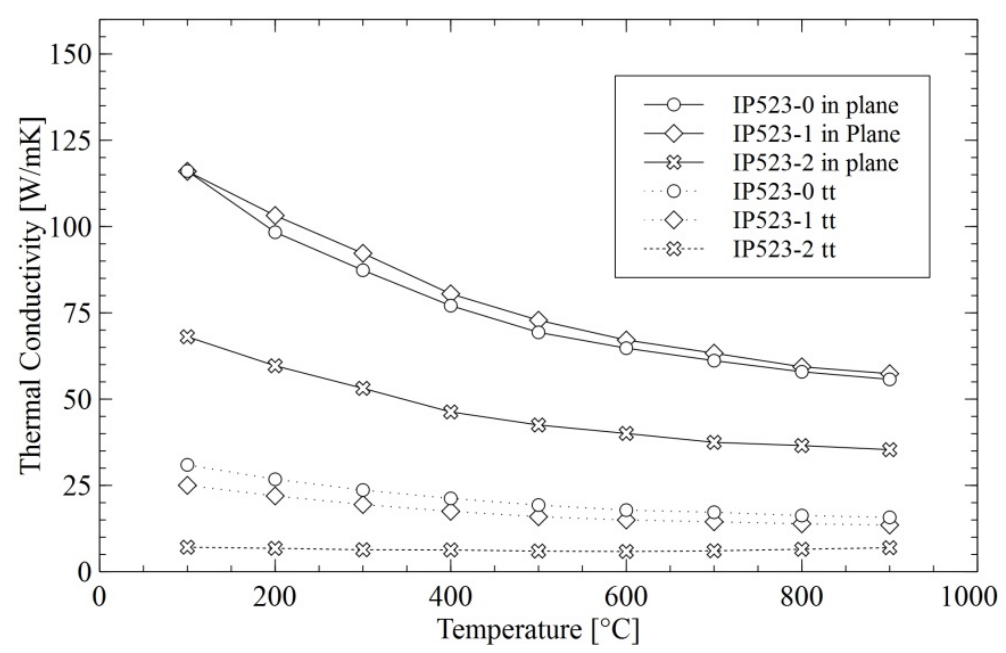

Figure 10. Thermal conductivity of IP523.

Here again, the behavior perpendicular to the fibers is dominated by the matrix properties with the sample having had no re-infiltration showing the highest conductivity values and the lower values for the samples with one and two re-infiltrations.

The highest thermal conductivity values were calculated for the IP527 samples as shown in Figure 11. The maximum value is $155 \mathrm{~W} / \mathrm{mK}$ at $100^{\circ} \mathrm{C}$ for the sample that was re-infiltrated twice. The samples which were not re-infiltrated and the ones with one re-infiltration show a similar conductivity of $140 \mathrm{~W} / \mathrm{mK}$ at $100^{\circ} \mathrm{C}$. The data perpendicular to the fibers is similar to that of IP521 and IP523 but on a slightly higher level with $35 \mathrm{~W} / \mathrm{mK}$ at $100^{\circ} \mathrm{C}$ as the maximum for the sample having had no re-infiltration and the lower values for the samples with one and two re-infiltrations. 


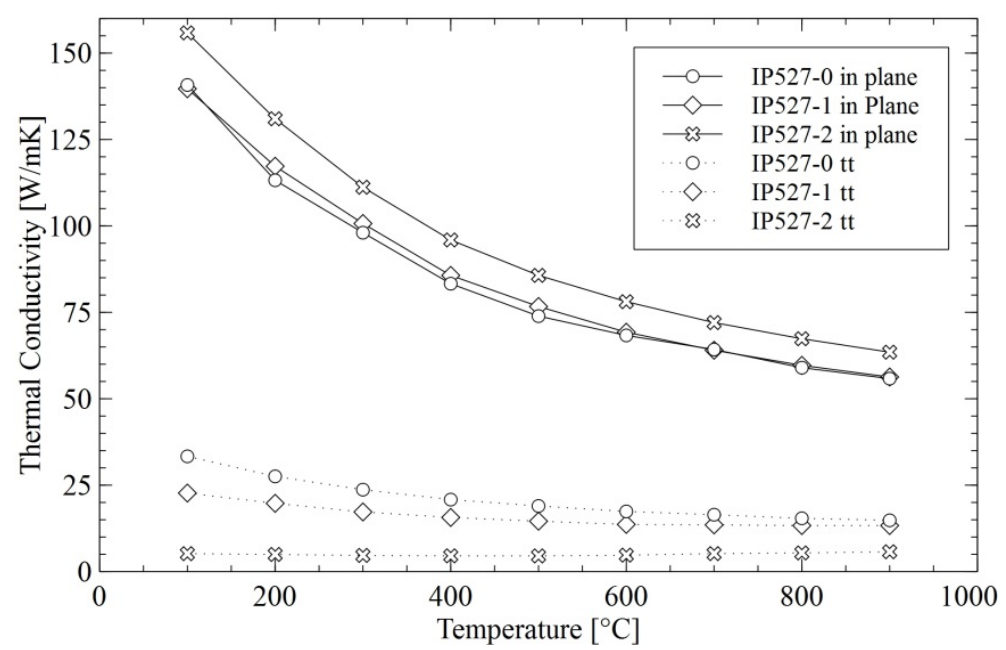

Figure 11. Thermal conductivity of IP527.

IP527 was made with the NGF fiber which results in a significantly higher conductivity than for IP521 and IP523 which were made with the Mitsubishi fiber. However, although the difference in thermal conductivity between the two fiber types is almost a factor of three, this is by far not reflected in the composite properties. A theoretical estimation was done in advance to determine which possible composite thermal conductivity could be achieved with the selected fibers. Using a simple approach in the form of

$$
\lambda_{\text {comp }, \text { long }}=0.5 \cdot F V C \cdot \lambda_{\text {fiber }}+0.5 \cdot F V C \cdot 0.236 \cdot \lambda_{\text {fiber }}+(1-F V C) \cdot \lambda_{\text {matrix }}
$$

yields a value of $100.76 \mathrm{~W} / \mathrm{mK}$ and $108.19 \mathrm{~W} / \mathrm{mK}$ for the composites produced with the Mitsubishi fibers and $237.87 \mathrm{~W} / \mathrm{mK}$ for the sample made with the NGF fiber. The constant of 0.236 was determined empirically to account for the fiber conductivity perpendicular to the fiber. In the composite an improvement of about $100 \mathrm{~W} / \mathrm{mK}$ can be achieved with this type of material. This is due largely to the microstructure of the material. $\mathrm{C} / \mathrm{C}$-SiC is a quite inhomogeneous material with different material phases as there are the bundles of carbon fibers, the matrix of $\mathrm{SiC}$ with inclusions of free silicon and a lot of cracks and pores which all create interfaces adding to thermal contact resistance.

The data indicates that the thermal conductivity of the single filament perpendicular to its axis is presumably much lower than along the filament axis. Data is difficult to obtain and not published by the suppliers. An effort is ongoing to establish such data via own measurements.

\section{MECHANICAL CHARACTERIZATION}

In order to evaluate the mechanical properties of the manufactured sample plates, threepoint short-beam bending tests were carried out. The results were compared between the new samples and to data of standard material that was produced earlier. The comparison plates were PH1659 and PH1815 reinforced with HTA fibers. As mentioned above, the results can be used to compare relative to other materials of a similar type but not in terms of absolute numbers. Mechanical properties of the fibers are given in Table IV. 
Table IV: Fiber properties

\begin{tabular}{|c|c|c|c|c|c|}
\hline Fiber & $\begin{array}{c}\text { Tensile } \\
\text { Strength } \\
{[\mathrm{MPa}]}\end{array}$ & $\begin{array}{c}\text { Young's } \\
\text { Modulus } \\
{[\mathrm{GPa}]}\end{array}$ & $\begin{array}{c}\text { Failure } \\
\text { Strain } \\
{[\%]}\end{array}$ & $\begin{array}{c}\text { Density } \\
{\left[\mathrm{g} / \mathrm{cm}^{3}\right]}\end{array}$ & $\begin{array}{c}\text { Filament } \\
\text { Diameter } \\
{[\mu \mathrm{m}]}\end{array}$ \\
\hline NGF YS-95A & 3530 & 920 & 0.3 & 2.19 & 7 \\
\hline $\begin{array}{c}\text { Mitsubishi } \\
\text { K63A12 }\end{array}$ & 2600 & 790 & 0.3 & 2.15 & 10 \\
\hline HTA & 3950 & 238 & 1.7 & 1.76 & 7 \\
\hline
\end{tabular}

The results of the short-beam bending test of IP521 are presented in Figure 12. The failure stress is around $170 \mathrm{MPa}$ for both samples which is about $15 \%$ less than the $200 \mathrm{MPa}$ reached with the standard material, however, it is on the same order of magnitude and more than was expected. Surprisingly, the failure strain is comparable or better than for standard material which was not expected. The sample without re-infiltration is already on par with PH1815 at $1.5 \%$ failure strain but for the sample with one re-infiltration an ever higher value of $2.1 \%$ could be reached. In addition, there is a noticeable nonlinear behavior at peak stress when failure begins and the strain increases on a relatively constant stress level.

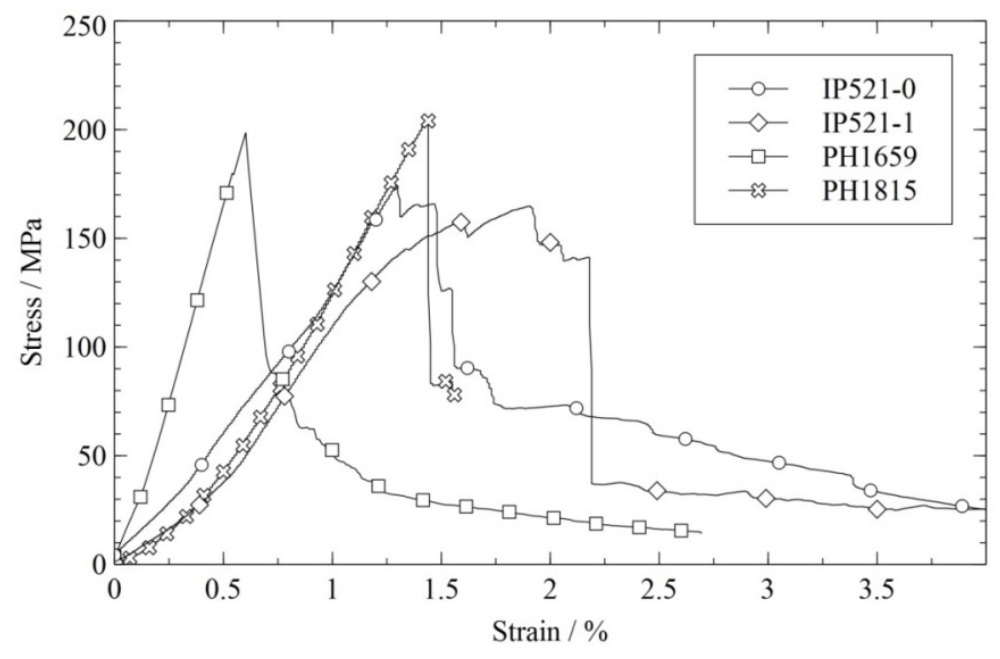

Figure 12. Results of short-beam bending tests for IP521.

The results of the tests with samples from IP523 are given in Figure 13. With these, the failure stress was around $150 \mathrm{MPa}$ which is $25 \%$ below the standard material values. There is again a nonlinear failure behavior to be observed for the sample with one re-infiltration. The ultimate failure strain is at $1.6 \%$ for this sample. The sample without re-infiltration showed a much higher failure strain of $2.4 \%$ at slightly over $150 \mathrm{MPa}$ but not the nonlinear failure behavior. 


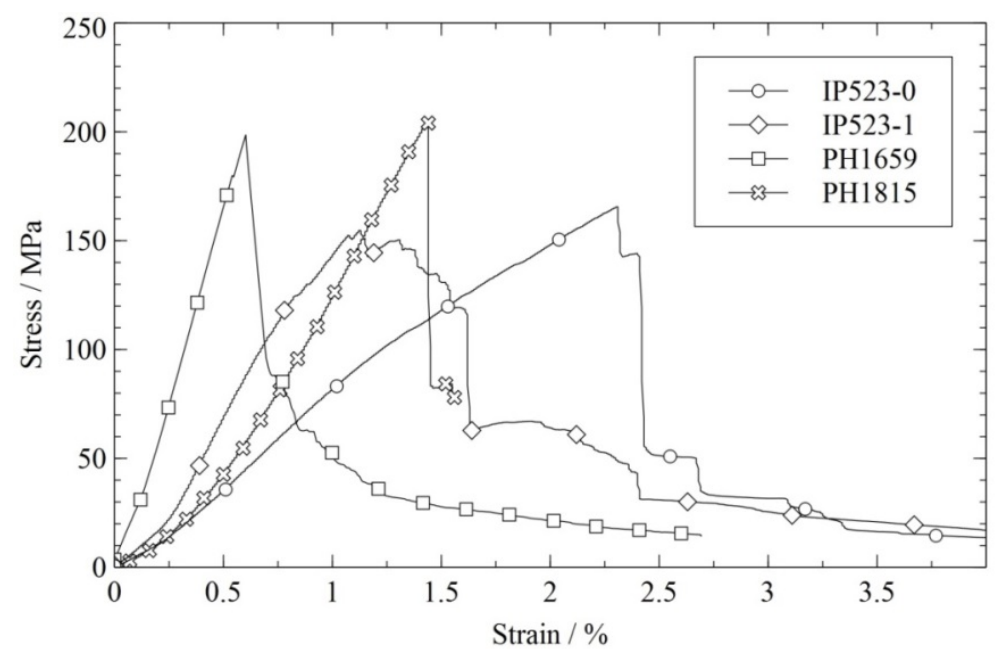

Figure 13. Results of short-beam bending tests for IP523.

The results of the bending tests with samples from IP527 are given in Figure 14. With these samples the failure stress was $250 \mathrm{MPa}$ for the sample with one re-infiltration and $285 \mathrm{MPa}$ for the sample without. This is remarkable because it is $25 \%$ and $42 \%$ higher than the failure stress for the standard material. For both material variants the failure strain is higher than for standard material. It was $2 \%$ for the sample with one re-infiltration and $3.2 \%$ for the sample without reinfiltration. The once-re-infiltrated sample shows a certain nonlinear failure behavior whereas the sample without re-infiltration shows a very steep failure without any sign of non-linearity.

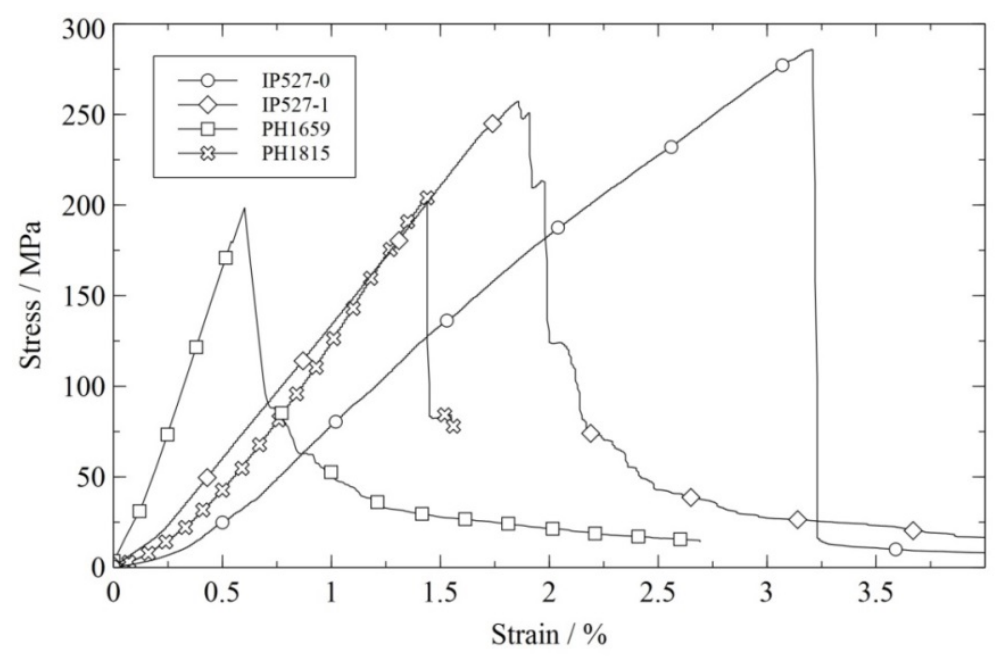

Figure 14. Results of short-beam bending tests for IP527.

The nonlinear failure of the samples with a quasi-ductile behavior indicates that there are typical fiber pull-out effects which dissipate the energy around the crack tip. In Figure 15 (a) an SEM image of the cracked sample IP527-1 is shown where a crack deflection can be seen. The crack is deflected when it reaches a fiber bundle and travels inside the fiber bundle without breaking it fully. At the next ply with a fiber-matrix-interface the crack is again deflected along the fibermatrix-interface. 


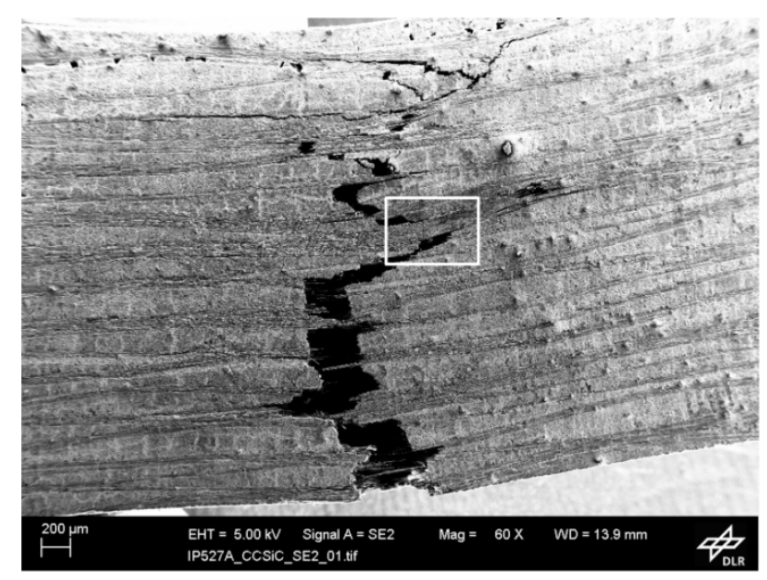

(a)

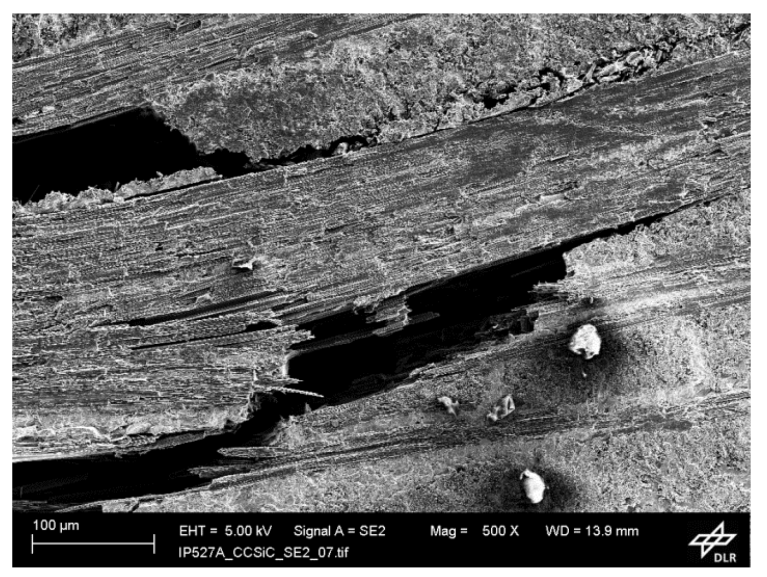

(b)

Figure 15. (a) Crack deflection (b) intact fiber bundle bridging over the crack.

The crack surface of the samples shows the pulled out fiber bundles as can be seen in Figure 16 (a) and there is an additional effect that was observed in the SEM investigations with regard to the fiber pull out. At high magnification it can be seen that there is a pull-out effect happening on the filament level.

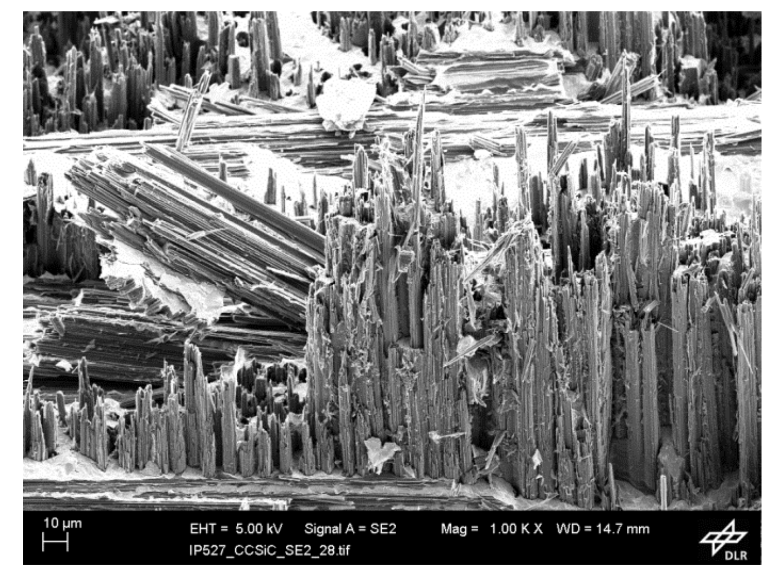

(a)

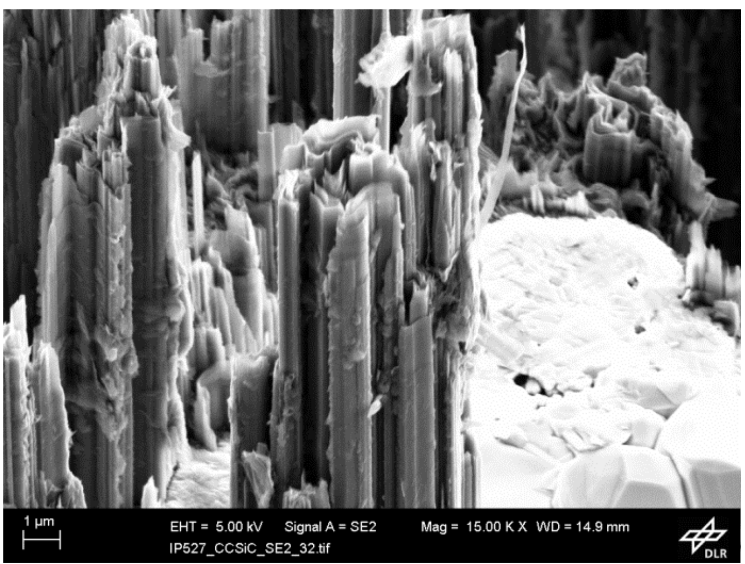

(b)

Figure 16. (a) Fiber pull-out on the crack surface, (b) broken fiber ends with layered structure.

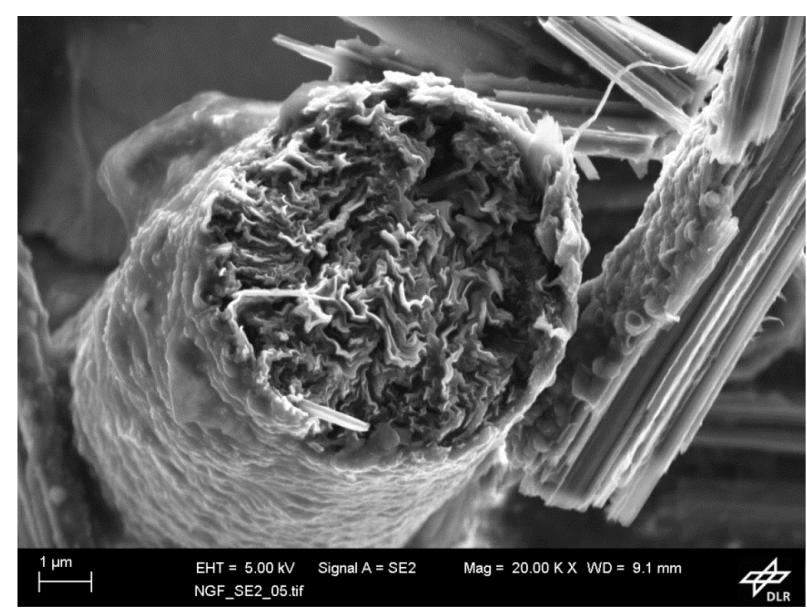

Figure 17. Internal layered structure of the NGF fiber. 
In Figure 16 (b) the broken ends of pulled-out fibers are visible. These fibers have a distinct morphology of individual layers and it is visible that the fibers are not cut off in one plane but the fiber layers seem to break individually with a possible relative movement between them creating a kind of intra-filament pull out effect. The internal layered structure of the NGF fiber is shown in Figure 17. This type of layered internal structure seems to be a typical feature of pitch carbon fibers.

\section{CMC MICROSTRUCTURE DISCUSSION}

The microstructure of the samples was analyzed via SEM. The images from the IP521 samples show that the microstructure is different from the standard. There are only little signs of a block formation in the fiber bundles and, in addition, there are lots of cracks throughout the blocks facilitating the access of liquid silicon to the single filaments during the siliconization. This leads to a finely dispersed matrix of silicon carbide as shown in Figure 18 (a). The silicon can react with the single filaments thereby converting a number of filaments completely into silicon carbide shown in Figure 18 (b).

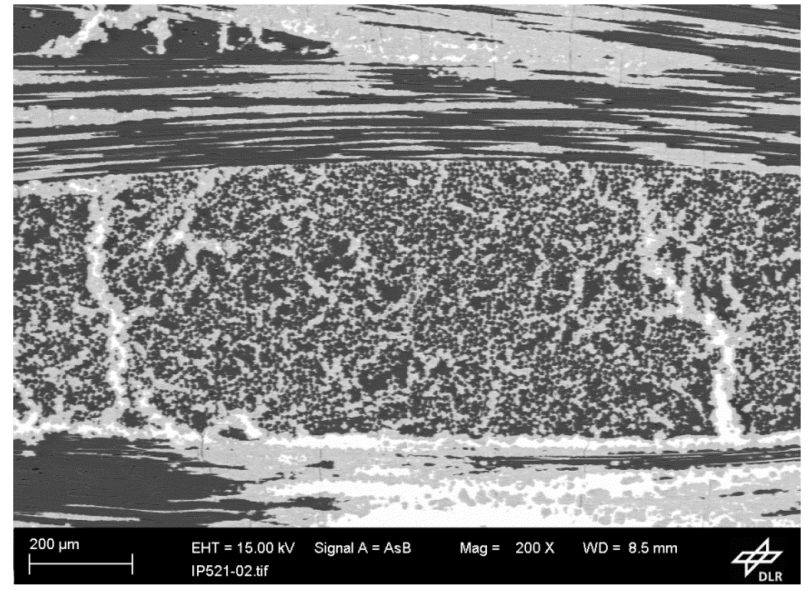

(a)

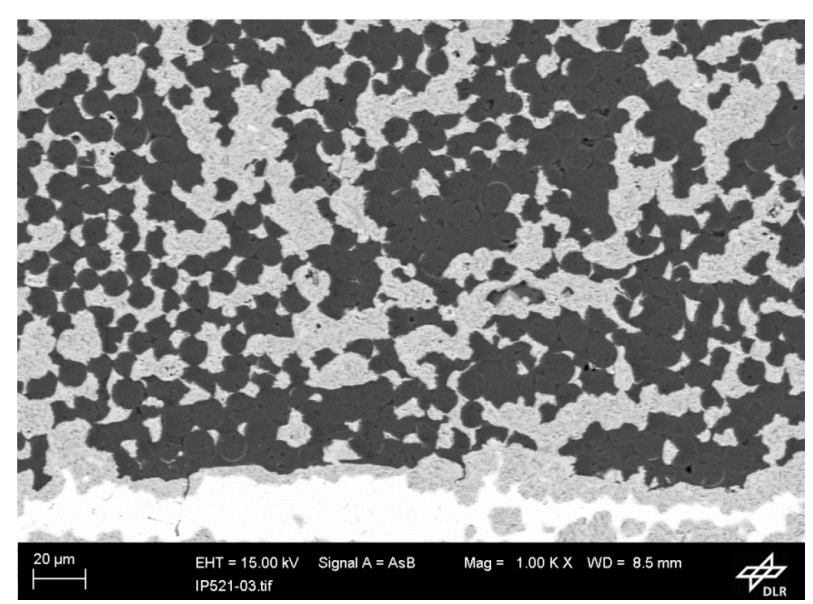

(b)

Figure 18. (a) Cross section of IP521-0 with silicon carbide in the fiber bundle, (b) magnification of IP521-0 with fibers partially consumed by silicon. Gray color is SiC, white color is free Si.

The effects of the re-infiltration cycles on the microstructure were not very strong for the first cycle. The SiC content was a little bit lower due to the lower porosity in the $\mathrm{C} / \mathrm{C}$ state.

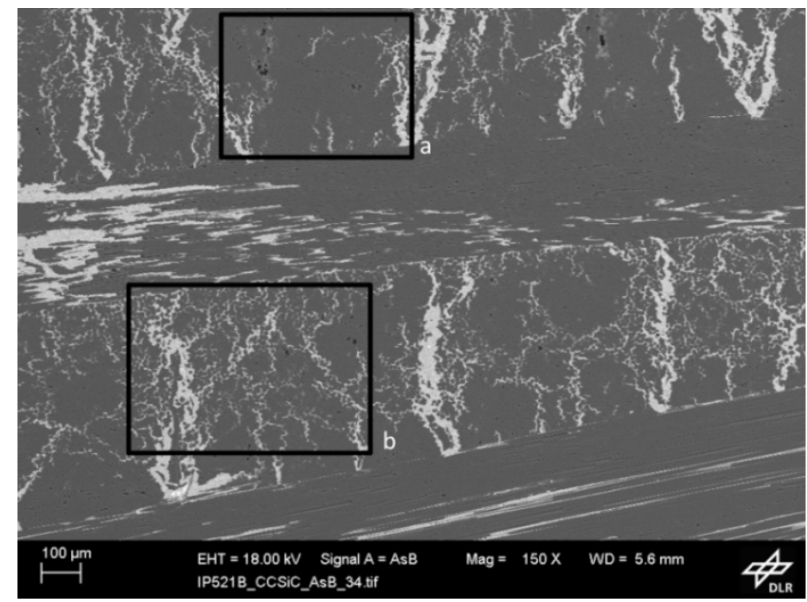

Figure 19. Inhomogeneous distribution of silicon carbide matrix in IP521-2 with regions low in $\mathrm{SiC}$ (a) and others rich in $\mathrm{SiC}$ (b). 
A stronger effect can be observed for the second re-infiltration. The amount of silicon uptake by the samples was considerably reduced due to the fact that the crack size was further narrowed by the re-infiltration. The images show that in that case the siliconization occurs not evenly distributed but regions develop with different properties. In Figure 19 it can be seen that there are regions with very little silicon carbide (a) but also regions with a high SiC-content (b). Observations similar to that for IP521 can be made for IP523. There is single-filament siliconization throughout the material shown in Figure 20 (a). The matrix conversion into silicon carbide is even more homogeneous than for IP521 which also results in the higher density of $2.47 \mathrm{~g} / \mathrm{cm}^{3}$ and the lower porosity of $0.98 \%$.

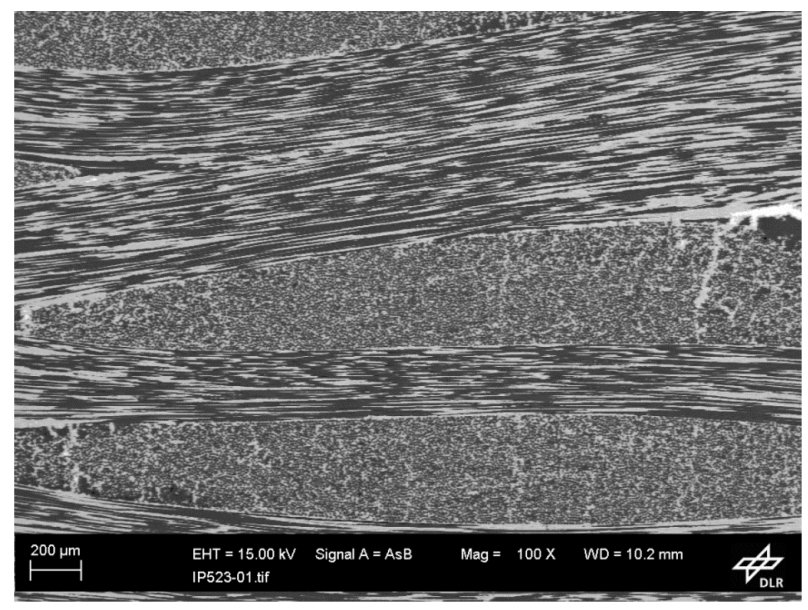

(a)

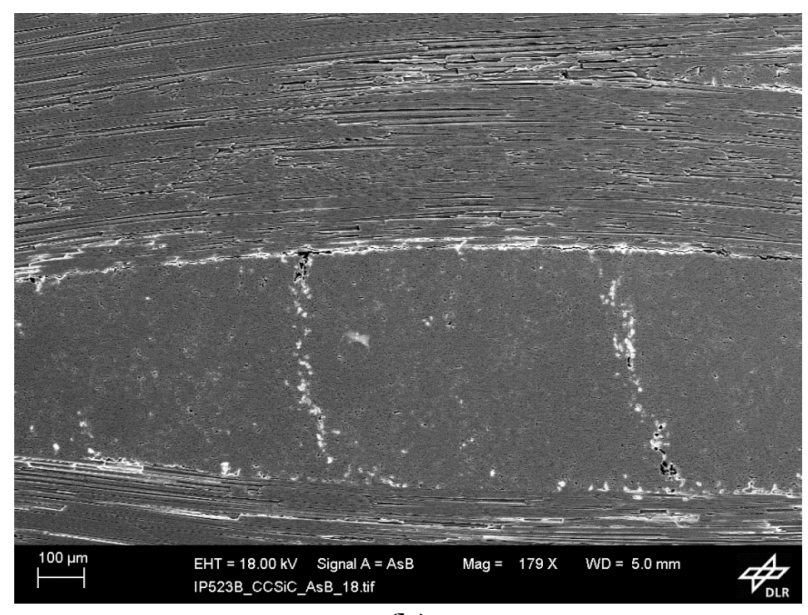

(b)

Figure 20. (a) Cross section of IP523-0 with finely dispersed matrix throughout the fiber bundles and (b) cross section of IP523-2 with large areas inside the fiber bundles still as C/C.

There is no principle difference between the samples without re-infiltration and the ones with one re-infiltration apart from the silicon content which is a bit lower for the samples with one reinfiltration. The sample that was re-infiltrated twice shows different properties which are reflected by the measured density and porosity. The Si-content and thus the density are low at $1.89 \mathrm{~g} / \mathrm{cm}^{3}$. The porosity is high at $8.01 \%$. The SEM images support the data. There is only a little amount of silicon that penetrated deeply into the material. In most regions the material still is more like $\mathrm{C} / \mathrm{C}$ than $\mathrm{C} / \mathrm{C}-\mathrm{SiC}$ as presented in Figure 20 (b).

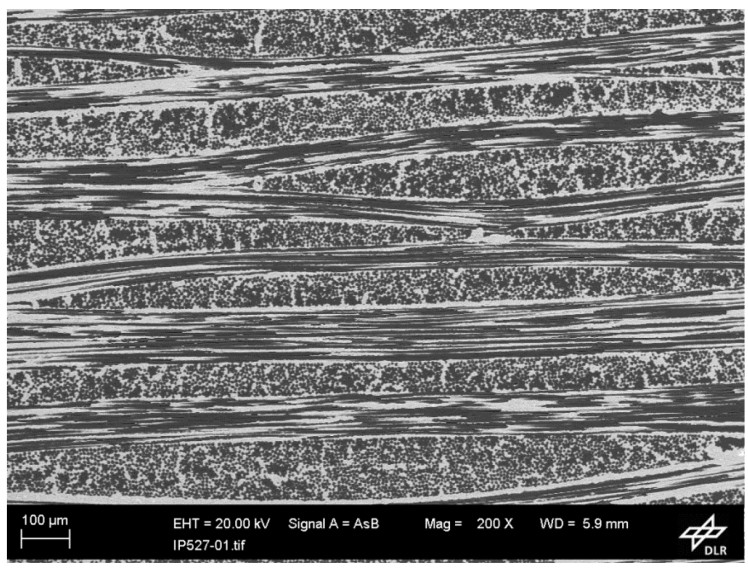

Figure 21. Cross section of IP527-0. 
Sample IP527-0 was not re-infiltrated and had a high density of $2.48 \mathrm{~g} / \mathrm{cm}^{3}$. With $65.8 \%$ it had the highest amount of silicon uptake of the samples produced in this study. The microstructure is similar to that of IP523-0 with single-filament siliconization as in Figure 21. Sample IP527-1 was re-infiltrated once. The microstructure also shows single-filament siliconization and is comparable to IP527-0, but the silicon uptake is lower with $37.4 \%$ leading to a somewhat lower density of $2.22 \mathrm{~g} / \mathrm{cm}^{3}$. Sample IP527-2 was re-infiltrated two times. As with the sample IP523-2, this results in a low silicon uptake of $16.4 \%$ and a high amount of porosity of $7.89 \%$ in the sample. The microstructure shows an inhomogeneous distribution of silicon carbide in the sample and large areas of $\mathrm{C} / \mathrm{C}$ that were not infiltrated with silicon at all comparable to IP521-2.

\section{DISCUSSION}

The measurement of the material data and the subsequent calculation of the thermal conductivity showed that values in the range of $150 \mathrm{~W} / \mathrm{mK}$ in fiber direction and $35 \mathrm{~W} / \mathrm{mK}$ perpendicular to the fibers can be achieved with the presented processing route. This is a considerable increase in thermal conductivity in comparison to the DLR standard C/C-SiC material which has a conductivity of $18 \mathrm{~W} / \mathrm{mK}$ in fiber direction and $9 \mathrm{~W} / \mathrm{mK}$ perpendicular to the fibers.

Initial trials had shown that the fiber-matrix interface is rather weak in the system of pitch carbon fibers and phenolic resin, leading to a fine crack network all through the fiber bundles and not to the desired large fiber blocks as with the standard materials. Therefore a processing route with multiple re-infiltration cycles was chosen to protect the filaments from being converted into silicon carbide by adding more carbon in the porosity created after the first pyrolysis cycle. This strategy worked out to a certain degree at least for the samples produced with one re-infiltration cycle. The samples that had been re-infiltrated twice with the resin were already too dense to take up enough silicon. The result was an incomplete siliconization with a resulting inhomogeneous distribution of silicon carbide in the matrix alongside with large regions where there was still C/C without silicon carbide.

When the thermal conductivity of $220 \mathrm{~W} / \mathrm{mK}$ and $600 \mathrm{~W} / \mathrm{mK}$ of the Mitsubishi and NGF fibers is considered is has to be admitted that it was not possible to transform the pure fiber properties into composite properties as desired. The materials produced showed surprisingly good mechanical properties when the microstructure is considered. Standard material with the type of microstructure usually exhibits brittle failure. The failure stress and strain were comparable or better than for standard material and the failure type showed clear indications of a quasi-ductile behavior.

\section{CONCLUSION}

Although the produced materials do not have the desired extremely high values in thermal conductivity especially at high temperatures, they still do have a thermal conductivity in the range of $150 \mathrm{~W} / \mathrm{mK}$ in fiber direction of the composite at room temperature and about 50-60 $\mathrm{W} / \mathrm{mK}$ at high temperature which is a considerable increase compared to the standard materials produced at DLR. In addition, the mechanical properties are better than expected and so there is good reason to continue the research and try to make better use of the pitch fiber properties in the composite. A specific treatment of the fiber surfaces seems to be key, which could be realized e.g. via a dedicated fiber coating.

\section{ACKNOWLEDGEMENTS}

The work was funded by the THERMAS research project of DLR. 


\section{REFERENCES}

1

D.M. Curry, W.C. Rochelle, D.C. Chao, P.C. Ting, Space Shuttle Orbiter Nose Cap Thermal Analysis, AIAA-86-0388 (1986).

5

T. Eggers, J.M.A. Longo, J. Turner, W. Jung, M. Hörschgen, A. Stamminger, A. Gülhan, F. Siebe, G. Requardt, T. Laux, T. Reimer, H. Weihs, The SHEFEX Flight Experiment Pathfinder Experiment for a Sky Based Test Facility, $14^{\text {th }}$ AIAA/AHI Space Planes and Hypersonic Systems and Technologies Conference, AIAA 2006-7921 (2006).

J. J. Bertin, Hypersonic Aerothermodynamics, AIAA 1993, ISBN 978-1563470363 (1993). IAF-01-I.3.01, 52nd International Astronautical Congress, Toulouse (2001).

S. Johnson, M. Gasch, M. Stackpoole, J.Lawson, M. Gusman, Recent Developments in Ultra High Temperature Ceramics at NASA Ames, $16^{\text {th }}$ AIAA International Space Planes and Hypersonic Systems and Technologies Conference, AIAA 2009-7219 (2009).

P. Kolodziej, J. Bull, J. Salute, D.L. Keese, First Flight Demonstration of a Sharp UltraHigh Temperature Ceramic Nosetip, NASA TM-112215 (1995).

H. Böhrk, Transpiration Cooling at Hypersonic Flight - AKTiV on SHEFEX II, $11^{\text {th }}$ AIAA/ASME Joint Thermophysics and Heat Transfer Conference, AIAA 2014-2676, (2014).

W. Krenkel, Carbon Fiber Reinforced Silicon Carbide Composites (C/SiC, C/C-SiC), Handbook of Ceramic Composites, Kluwer Academic Publishers (2005)

S. Chand, Review Carbon fibers for composites, J. Materials Science, 35, 1303-1313 (2000).

E. Fitzer, Pan-based carbon fibers - present state and trend of the technology from the viewpoint of possibilities and limits to influence and to control the fiber properties by the process parameters, Carbon, 27, Issue 5, 621-645 (1989) 